\title{
TABLE DES PLANCHES
}

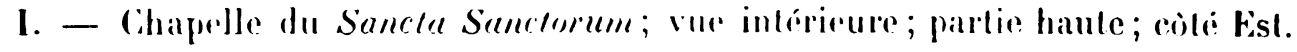 \\ II. - Chapelle du Sancta Sanctorum; vur intérieure; partie haute; côté Ouest. \\ III. - Chapelle du Sancta Sanctorum; vue intérieure; partie haute; côté Nord. \\ IV. - Chapelle du Sancta Sanctorum; vue intéricure; partic haute; còté sud. \\ V. - lcòne achiropoète du Christ. \\ VI. - Croix d'émail cloisonné des papes Symmaque et Serge I'r (?) (vie-vile siècle). \\ VII. - Coffret d'argent rectangulitire renfermant la croix d'émail (couvercle et quatre \\ faces latérales).
}

VIII. - Croix d'or gemméc dite " de la Circoncision "; don de Charlemagne au palp" Hadrien (?).

IX. - Coffret d'argent cruciforme du pape Pascal ler (817-8:' $)$, renfermant la Ciroix de la Circoncision.

X. - Coffret dargent byzantin renfermant le chef de sainte Praxide. Son couvercle orné d'émaux (à plus grande échelle).

XI. - 1. Objets divers et fragment d'étain orné de reliefs. - 2. Couvercle du coftret d'argent renfermant le chef de sainte $\mathbf{A g n e ̀ s . ~ - ~ 3 . ~ " ~ I g n u s ~ D e i ~ " ~ e n ~ c i r e . ~ - ~}$ 4. Nuthentique du $x^{e}$ siècle, parchemin et sceau de terre avec la Guérison du paralytique. - 5. Ampoule de verre et colonnette d'ivoire. - 6-7. Coffret d'argent byzantin; cordes scellées de l'anneall du pècheur de Nicolas III (1277-1280).

XII. - Reliquaires de métal. - 1. Coffret d'argent doré et nielló (deux faces). - 2. Coffret de cuivre (couvercle avec Crucifixion émaillée). - 3. "Capsella " d'argent (deux faces). 